\title{
Structural and thermal degradation behaviour of reclaimed clay nano-reinforced low-density polyethylene nanocomposites
}

\author{
Shohel Siddique ${ }^{1} \cdot$ Grant David Smith $^{1} \cdot$ Kyari Yates $^{2} \cdot$ Ajay Kumar Mishra $^{3} \cdot$ Kerr Matthews $^{2} \cdot$ Laszlo J Csetenyi $^{4}$. \\ James Njuguna ${ }^{1}$ [D
}

Received: 27 November 2018 / Accepted: 29 April 2019 / Published online: 1 June 2019

(C) The Author(s) 2019

\begin{abstract}
In this study, a novel reclaimed clay nanofiller was used to manufacture low-density polyethylene (LDPE)/Oil based mud filler (OBMF) nanocomposites by a melt compounding process. The mechanical testing samples were manufactured using injection moulding. The effect of reclaimed clay minerals influencing the crystallinity and the dispersion characteristics of this clay in LDPE matrix affecting the structural and thermal properties of the nanocomposites was investigated. It was observed that OBMFs were compatible with LDPE matrix which implies a strong interfacial interaction between the clay layers and polymer and that the influence of clay minerals present in OBMFs formed chemical bonds within the microstructure of the nanocomposites. The char yields of nanocomposites increased with OBMFs content. The $\mathrm{T}_{\mathrm{D} 5 \%}$ and $\mathrm{T}_{\mathrm{D} 50 \%}$ (onset degradation temperature at $5 \mathrm{wt} \%$ loss and $50 \mathrm{wt} \%$ loss, respectively) of the LDPE nanocomposite with $10.0 \mathrm{wt} \%$ OBMFs was the highest $\left(27^{\circ} \mathrm{C}\right.$ higher in $\mathrm{T}_{\mathrm{D} 5 \%}$ and $54{ }^{\circ} \mathrm{C}$ higher in $\mathrm{T}_{\mathrm{D} 50 \%}$ ) among the nanocomposites. Viscoelastic analysis data showed a sharp decrease in the storage modulus of OBMFs reinforced LDPE nanocomposites. The $\tan \delta$ spectra presented a strong influence of the filler contents on the relaxation process of LDPE and its nanocomposites. An enhancement of mechanical properties of composites was identified which showed a gain of $14 \%$ Young's modulus and a gain of $18 \%$ tensile strength at $10.0 \mathrm{wt} \%$ OBMFs loading compared to those properties of neat LDPE. The effect of filler dispersion in LDPE polymer matrix in relation to thermal stability was investigated and heat capacity data is employed to characterise changes in thermal characteristics relating to the nanomorphology of the materials.
\end{abstract}

Keywords OBMFs · Thermal stability · Thermal degradation · Crystallinity; rigid amorphous fraction; mobile amorphous fraction

\section{Introduction}

Incorporation of fillers in polymer matrix is an interesting area of research in recent years [1,2]. This addition of fillers is not

James Njuguna

j.njuguna@rgu.ac.uk

1 Centre for Advanced Engineering Materials, School of Engineering, Robert Gordon University, Riverside East, Garthdee Road, Aberdeen AB10 7GJ, UK

2 School of Pharmacy and Life Sciences, Robert Gordon University, Aberdeen AB10 7GJ, UK

3 Nanotechnology and Water Sustainability Research Unit, College of Science, Engineering and Technology, University of South Africa, Florida Campus, Johannesburg, South Africa

4 School of Science and Engineering, University of Dundee, Dundee DD1 4HN, UK limited to saving costs, it improves the mechanical, thermal and flammability properties too [3]. The addition of fillers is function-specific $[4,5]$ such as adding clay in enhancing physical, thermal, and mechanical properties of polymer matrix [6]. Polymer/clay nanocomposites have drawn an enormous interest recently due to significantly influencing on the physical, thermal, mechanical and flame retardancy properties of nanocomposites [7-10]. Findings from the literature highlight that layered silicate fillers provide the most successful results by acting as nano-filler precursors [11-13]. However, the literature findings are very limited resulting in an information gap to understand the effect of this nanoclay in influencing the physical, thermal, mechanical, and flame retardancy properties of low density polyethylene (LDPE) polymer in details.

LDPE is produced on a large industrial scale and one of the most widely consumed polymer materials due to its excellent and desirable properties such as light weight, low cost, low dielectric constant and losses, high chemical resistance and 
easy manufacturing process $[14,15]$. However, the use of LDPE is still limited due to its inherent chemical nature [16], poor thermal stability and flammability [17, 18]. Improvement of the thermal and flammability properties of synthetic polymeric materials such as LDPE is desirable to replace more traditional inorganic and natural polymeric materials $[16,19]$. For this improvement, it is common practice to apply flame retardant additives within the polymer matrix. However, some flame retardant additives are considered harmful for the environment and hence have been phased out $[20,21]$. Considering the stringent environmental regulations and the need to improve thermal and flammability properties of the polymers, development of an alternative environmentally friendly flame retardant material is becoming an area of polymer research interest [22].

Utilising industrial by-products as a filler in nanocomposite manufacturing is an area or research interest in recent years. Waste fly ash [23], waste iron ore tailing [24], waste pineapple leaves [25], coir [26], waste rubber powder [27], waste husks ash [28] etc. are predominantly considered as a sustainable source of filler for improving different properties in polymers. In view of the different influential effects of clay minerals on mechanical, thermal and flame retardancy behaviour of nanocomposite materials, the recovery of significant amount of nanoclays in waste drilling fluids warrant investigations. This study was inspired by the use of less explored LDPE polymer matrix incorporated with addition of reclaimed clay from oil based mud waste in the oil and gas industry as a nanofiller.

In oil and gas industry, driling through rock generally requires the use of some type of fluid to clear cuttings from the borehole formed by the drill. In some applications, the drilling fluid can be as simple as compressed air. However, when drilling is conducted to tap fossil fuel resources, the drilling fluid has to be an actual fluid [29]. The drilling fluid (also called drilling mud) is an essential component of the drilling process. In most deep drilling operation, oil based fluids (OBMFs) are used instead of water based fluids (WBFs) depending on the drilling conditions for efficient and cost-effective operations [30]. It is quite common practice to use both WBFs and OBMFs in drilling the same well, with WBFs for shallow portion of the well and OBMFs for deep drilling [31]. The well drilling process produces waste drilling fluid composed of drill cuttings and spent mud waste. When the drilling process is finished, the drilling fluid waste is composed e.g. of drilling fluid, cuttings, water, oil and many additives. The sources of drilling wastes largely depend on the cuttings based on the geological condition of the borehole, the depth of the well, and the fluid used in the drilling operation [32].

This study focuses on the reclamation and usage of layered silicates from oil based mud (OBM) waste, in particular their utilisation in engineering nanocomposite materials, specifically in low-density polyethene (LDPE) matrix. Detailed investigations were performed to identify the dispersion characteristics of OBMFs in LDPE polymer matrix based on the thermal analysis results, which also lead to highlighting the rigid amorphous fraction (RAF), mobile amorphous fraction (MAF) and percentage of crystallinity along with the mechanical property study.

\section{Experimental}

\section{Materials}

Lupolen $1800 \mathrm{~S}$ (trade name of LDPE) polymer was supplied by Northern Polymers and Plastics Ltd., UK. It has a melting point of $106^{\circ} \mathrm{C}$ and a V-2 rating in accordance with UL 94 (vertical burning test) at $1.6 \mathrm{~mm}$ thickness. The spent oil based mud (OBM) was donated by a local oil and gas company. Montmorillonite, K10 powder was purchased from SigmaAldrich, UK and used as reference material in sample analysis.

\section{OBMFs manufacturing process}

Filler was recovered from OBM waste in a series of thermal treatments. The first treatment involved heating the OBM at $50{ }^{\circ} \mathrm{C}$ for $12 \mathrm{~h}$ to eliminate as much of the petroleum fraction as possible. The temperature was then increased to $80^{\circ} \mathrm{C}$ for a further $12 \mathrm{~h}$. Recovery of the solid content was enhanced by decanting oil-water mixture from the top of the sample. In the second stage of recovery, the furnace temperature was increased to $700{ }^{\circ} \mathrm{C}$ and held for a further $12 \mathrm{~h}$ to vaporise the remaining heavy oil fractions. Only the solid content of the OBM waste was recovered. The recovered mud was milled to a powder using ball mill (Ultra Turrax, IKA).

\section{LDPE/OBMFs nanocomposite manufacturing process}

LDPE/OBMFs nanocomposites were manufactured by using a commercially available LDPE and recovered OBM clay. The filler concentrations used in this study were are $2.5 \mathrm{wt} \%, 5.0 \mathrm{wt} \%, 7.5 \mathrm{wt} \%$ and $10.0 \mathrm{wt} \%$. LDPE Polymer in pellet form and OBMFs were dried at $90{ }^{\circ} \mathrm{C}$ overnight prior to melt compounding. Melt compounding of different wt $\%$ of concentrations of OBMFs with LDPE was carried out using TwinTech Extrusion Ltd. $10 \mathrm{~mm}$ twin screw extruder at $60 \mathrm{rpm}$ over five heating zones: 1 st zone $\left(120{ }^{\circ} \mathrm{C}\right)$, 2nd zone $\left(200{ }^{\circ} \mathrm{C}\right)$, 3rd zone $\left(210{ }^{\circ} \mathrm{C}\right)$, 4th zone $\left(200{ }^{\circ} \mathrm{C}\right)$ and die/5th zone $\left(200{ }^{\circ} \mathrm{C}\right)$. The compounded granules were prepared by using a pelletiser which were then injection moulded into a bar mould (dual cavity) for different 


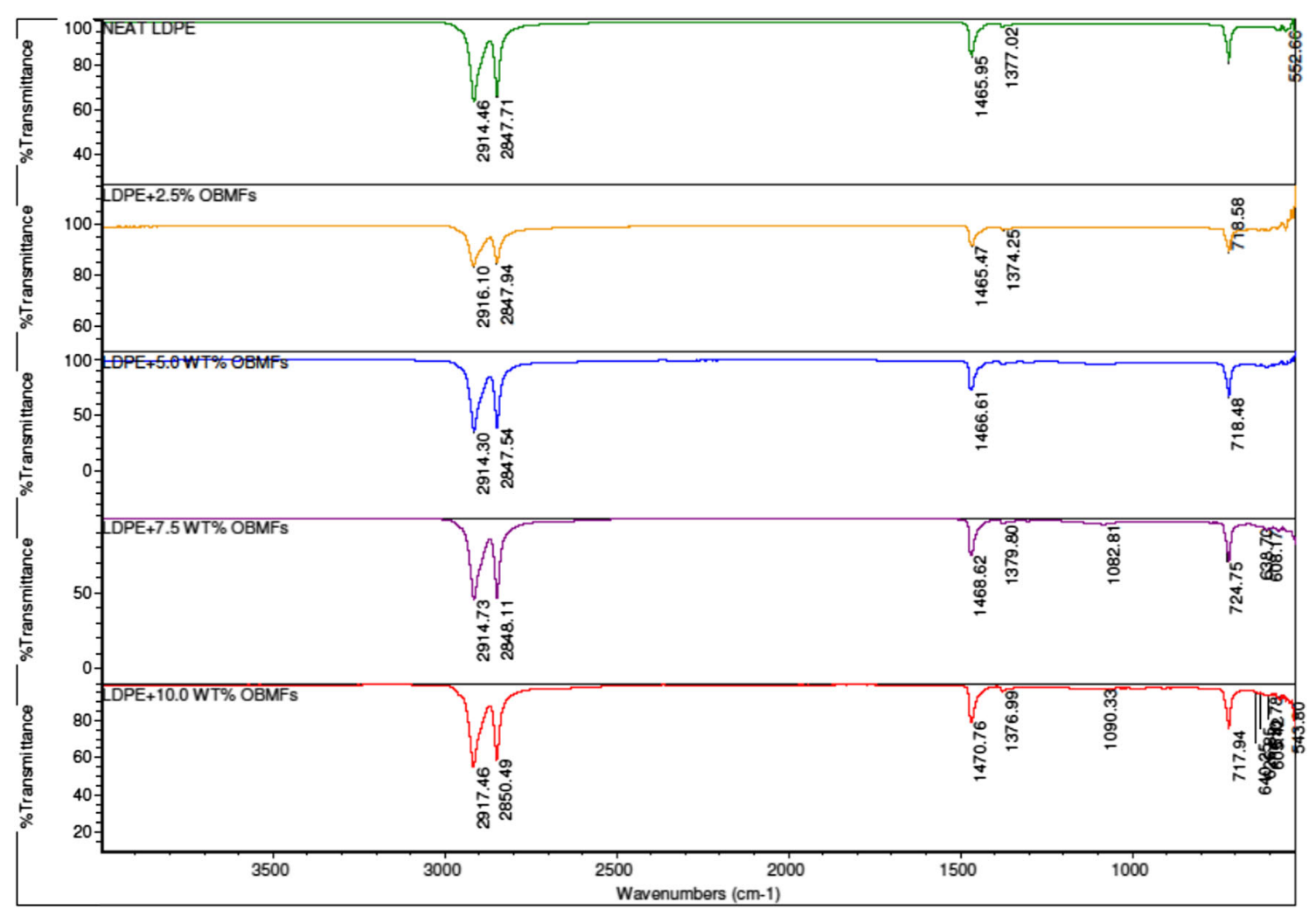

Fig. 1 Comparison of ATR-FTIR common scale spectra of LDPE and its nanocomposite

analyses using a temperature of $230{ }^{\circ} \mathrm{C}$ with a moulding pressure of 10 bar. The samples were then left to cool to room temperature before submitting to different analysis and characterisation processes.

\section{Sample characterisation}

To observe the morphology of OBMFs and their dispersion characteristics in LDPE polymer matricesx, a cryogenic sampling technique was has been followed for sample preparation. The fractured samples were gold coated using sputter deposition for 2 min prior to the

Table 1 ATR-FTIR peak assignments of LDPE and its nanocomposites

\begin{tabular}{ll}
\hline Wave number $\left(\mathrm{cm}^{-1}\right)$ & Assignments \\
\hline 2914 & $\mathrm{CH}_{2}$ stretching \\
2850 & $\mathrm{CH}_{2}$ stretching \\
1465 & bending of $\mathrm{CH}_{2}$ \\
1377 & inter layer carbonate ions \\
1082 & stretching of Si-O \\
718 & rocking of $\mathrm{CH}_{2}$ \\
$640,630,608$ & oxide bands of metals like $\mathrm{Si}, \mathrm{Al}, \mathrm{Mg}$, etc. \\
$525-580$ & $\delta(\mathrm{M}-\mathrm{O}-\mathrm{M})$ clay \\
\hline
\end{tabular}

experiment. The fractured sample sections were observed using a Zeiss EVO LS10 Scanning Electron Microscope (SEM) with a magnification of $250 \mathrm{x}$, $4.5 \mathrm{~mm}$ working distance and $25.00 \mathrm{kV}$ accelerating potential. To determine the approximate elemental composition of the samples, energy dispersive $\mathrm{x}$-ray analysis (EDXA) (Oxford Instruments INCA Energy) was carried out. The morphology of cryo-fractured samples were analysed using SEM and EDXA. Attenuated Total Reflectance-Fourier Transform Infra-Red spectroscopy was performed using a Thermo Scientific Nicolet iS10 FTIR Spectrometer setting for 32 scans between 4000 and $400 \mathrm{~cm}^{-1}$. The influence of water vapour and carbon dioxide in air was minimised by subtracting peaks from blank measurement.

To identify the degradation and decomposition behaviour of neat LDPE and LDPE/OBMFs nanocomposites, ThermoGravimetric Analysis (TGA) was carried out using a TA TGA Q500 instrument. This analysis represented the weight variation of a measured sample on ramp mode from room temperature $\left(31.1^{\circ} \mathrm{C}\right)$ to $1000{ }^{\circ} \mathrm{C}$ at a rate of $10{ }^{\circ} \mathrm{C}$ per minute. To ascertain the glass transition, melting and crystallisation phases of the materials, Differential Scanning Calorimetry (DSC) was carried out using a TA Q100 instrument by adopting the heat-cool-heat method. The principle of this method is to determine the heat exchange difference between 


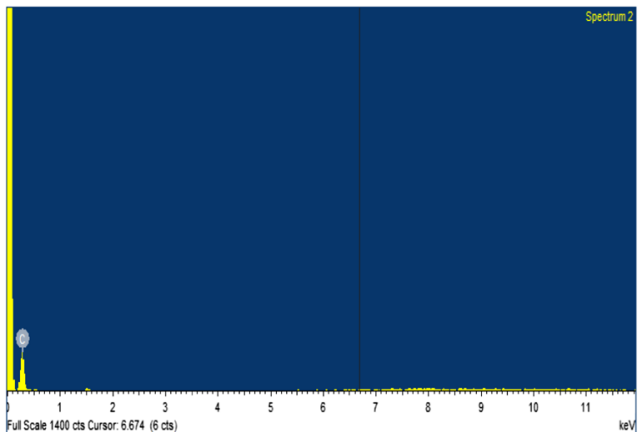

\begin{tabular}{|l|r|}
\hline Element & Atomic\% \\
\hline $\mathrm{C}$ & 87.42 \\
\hline $\mathrm{O}$ & 12.58 \\
\hline Totals & 100 \\
\hline
\end{tabular}

(a)

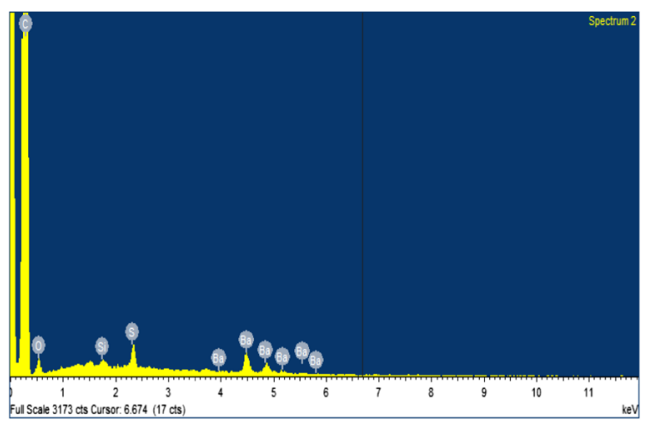

\begin{tabular}{|l|r|}
\hline Element & Atomic\% \\
\hline $\mathrm{C}$ & 96.14 \\
\hline $\mathrm{O}$ & 3.29 \\
\hline $\mathrm{Si}$ & 0.06 \\
\hline $\mathrm{S}$ & 0.23 \\
\hline $\mathrm{Ba}$ & 0.28 \\
\hline Totals & 100 \\
\hline
\end{tabular}

(b)
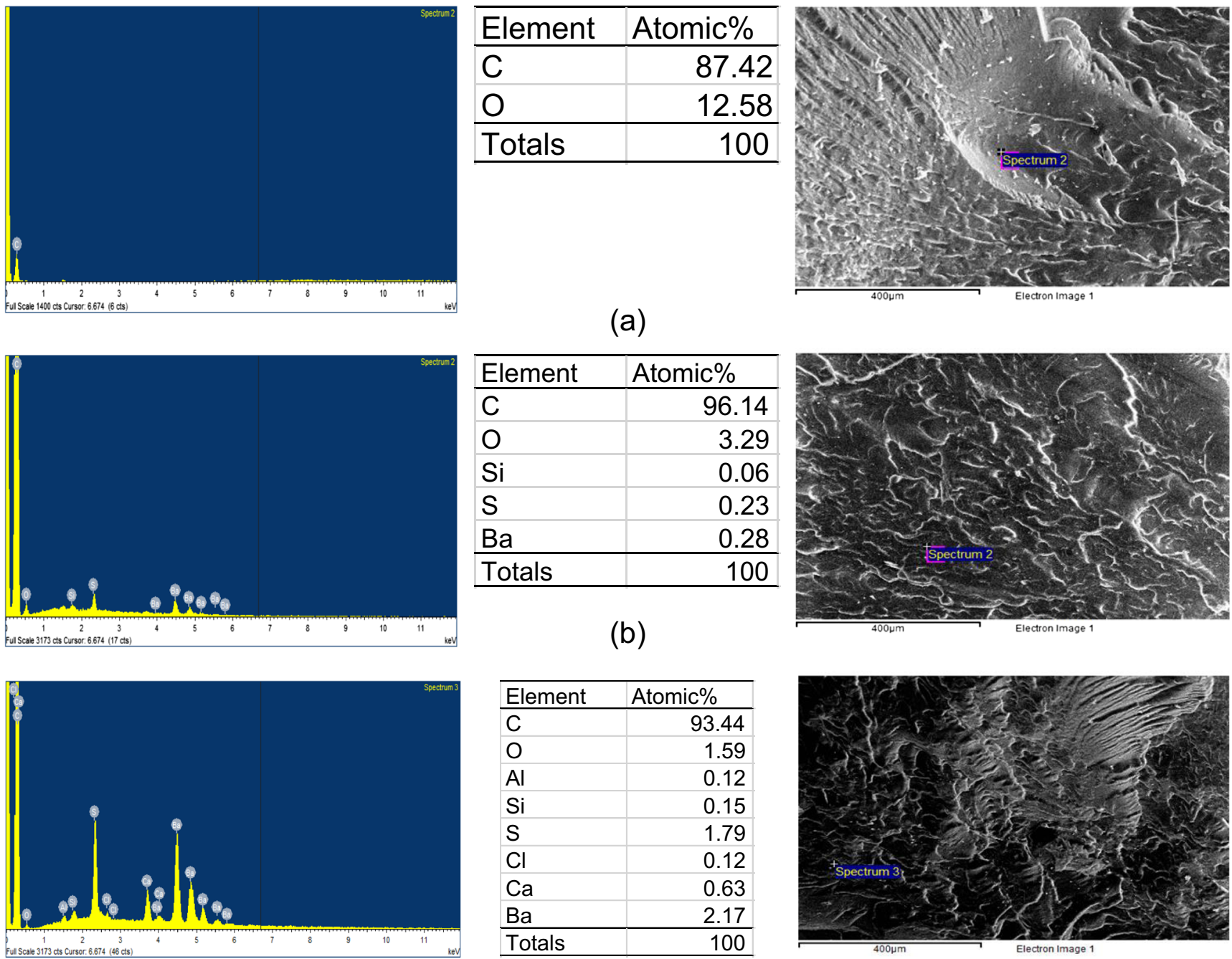

\begin{tabular}{|l|r|}
\hline Element & Atomic\% \\
\hline $\mathrm{C}$ & 93.44 \\
\hline $\mathrm{O}$ & 1.59 \\
\hline $\mathrm{Al}$ & 0.12 \\
\hline $\mathrm{Si}$ & 0.15 \\
\hline $\mathrm{S}$ & 1.79 \\
\hline $\mathrm{Cl}$ & 0.12 \\
$\mathrm{Ca}$ & 0.63 \\
\hline $\mathrm{Ba}$ & 2.17 \\
\hline Totals & 100 \\
\hline
\end{tabular}

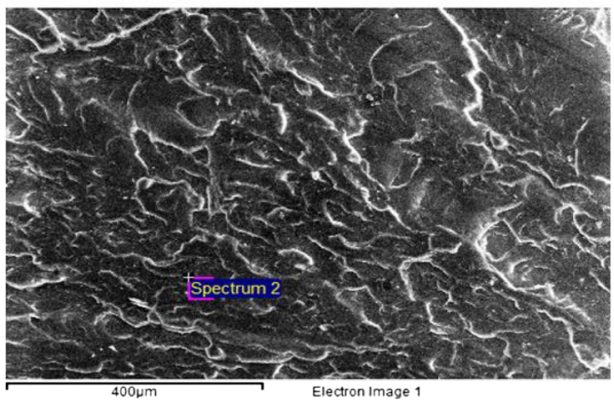

(c)

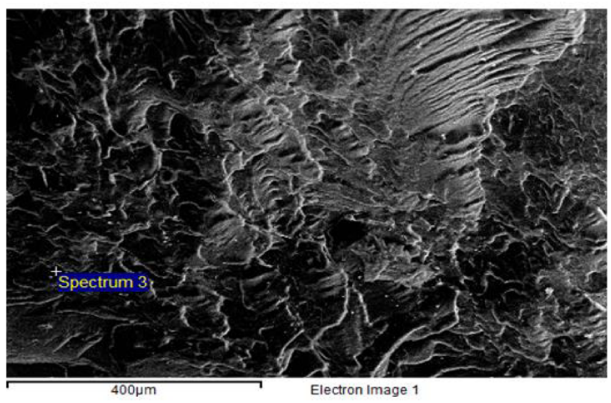

Fig. 2 EDXA spectra of (a) LDPE; (b) LDPE+2.5 wt\% OBMFs; (c) LDPE+5.0 wt\% OBMFs; (d) LDPE+7.5 wt\% OBMFs and (e) LDPE+10.0 wt\% OBMFs

the sample and the reference pan (an empty aluminium pan). The temperature was set from $-20^{\circ} \mathrm{C}$ to $250{ }^{\circ} \mathrm{C}$ at a rate of $10{ }^{\circ} \mathrm{C}$ per minute.

XRD analysis was carried out on a Siemens D5000 diffractometer with $\mathrm{Cu} \mathrm{K} \alpha$ radiation $(\lambda=0.15418 \mathrm{~nm})$ and $0.05^{\circ} 2 \theta$ step size. The scan angle covered the range from $3^{\circ}$ to $60^{\circ} 2 \theta$ for layer materials and nanocomposites at a scan speed of $2^{\circ} \mathrm{min}^{-1}$. The dispersion morphology of the nanocomposites was measured by Transmission electron microscopy (TEM), obtained on a JEOL JEM2010, $200 \mathrm{kV}$. An $80 \mathrm{~nm}$ thickness sample was prepared by using a Leica Ultracut-UCT microtome without any staining.

Dynamic shear measurements were obtained with a rheometer (AR 1000, TA Instruments) using a parallel plate geometry ( $8 \mathrm{~mm}$ diameter and $3.1 \mathrm{~mm}$ gap). Samples were tested to identify the viscoelastic properties as a function of temperature. The temperature range used in this study was varied from 0 to $90{ }^{\circ} \mathrm{C}$, with a heating rate of $3{ }^{\circ} \mathrm{C} / \mathrm{min}$ the samples were scanned at a fixed frequency of $1 \mathrm{~Hz}$, with a strain of $0.2 \%$.

\section{Testing}

Tensile and flexural (3-point bending) tests were carried out using Instron 3382 universal testing machine connected with Bluehill 3 software. The load was measured using a $100 \mathrm{kN}$ load cell. Tensile experiment was conducted using the dog-bone shaped samples which were prepared as per ASTM method D-638 and flexural experiment was conducted according to The European Standard EN ISO 14125. All tests were conducted at constant strain rate of $2 \mathrm{~mm} / \mathrm{min}$ and the data presented here is the average of 5 samples. 

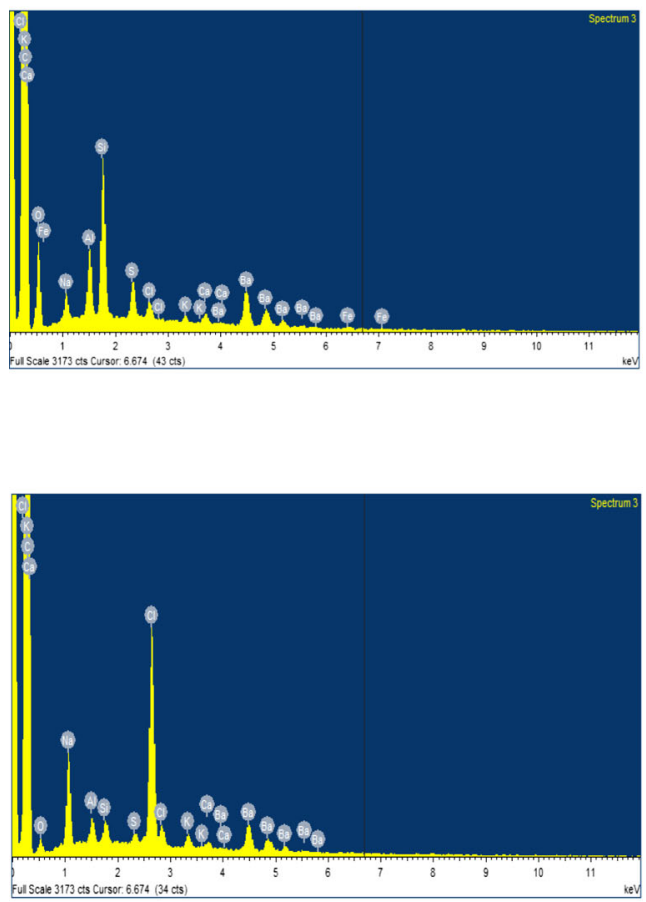

Fig. 2 (continued)

\section{Results and discussion}

\section{Elemental analysis of nanocomposite materials using ATR-FTIR study and EDXA}

The ATR-FTIR spectrum analysis of neat LDPE and its nanocomposite has been carried out and the resulting spectra are presented in Fig. 1.

A summary of ATR-FTIR peak assignments is presented in Table 1 based on information published in the literature [16, 33-36].

The chemical structure of LDPE/OBMFs nanocomposites has been identified by using ATR-FTIR which shows the IR transmittance peaks at $2914 \mathrm{~cm}^{-1}$ and $2850 \mathrm{~cm}^{-1}$ corresponding to $\mathrm{CH}_{2}$ stretching, the peaks at $1465 \mathrm{~cm}^{-1}$ and $718 \mathrm{~cm}^{-1}$ representing to the bending and rocking of $\mathrm{CH}_{2}$, respectively. The peaks at $1377 \mathrm{~cm}^{-1}$ highlight the presence of interlayer carbonate ions. The peak at $1082 \mathrm{~cm}^{-1}$ represents the stretching of $\mathrm{Si}-\mathrm{O}$, and the peaks at $640 \mathrm{~cm}^{-1}, 630 \mathrm{~cm}^{-1}$ and $608 \mathrm{~cm}^{-1}$ correspond to the oxide bonds of metals such as $\mathrm{Si}, \mathrm{Al}, \mathrm{Mg}$ etc. The peak at $580-525 \mathrm{~cm}^{-1}$ represents the crystalline forms of rare earth oxides which is observed in LDPE nanocomposite samples with 5.0, 7.5 and 10.0 wt\% OBMFs content. It can articulate that the peaks at lower bands between 640 and $540 \mathrm{~cm}^{-1}$ correspond to the chemical structure formed by different minerals present in the OBMFs nanoclay.

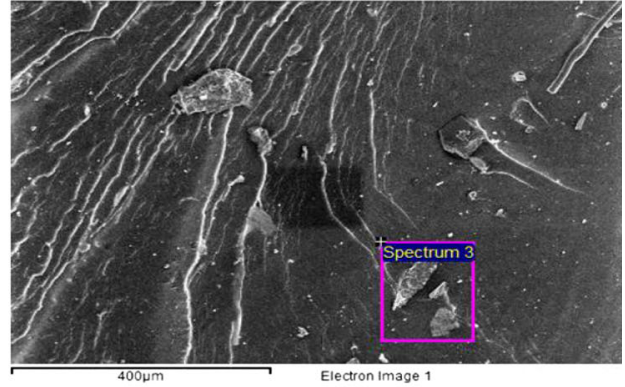

(d)

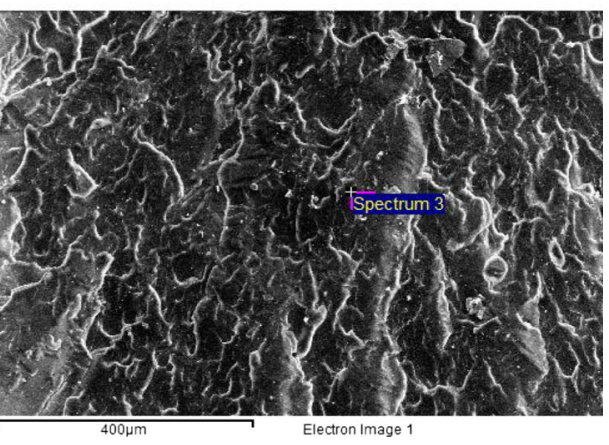

(e)
To identify the elemental composition and explain the addition of OBMFs in the LDPE polymer matrix, Energy Dispersive X-ray (EDXA) analysis was carried out as presented in Fig. 2a-e.

Figures $2 \mathrm{a}-\mathrm{e}$ show the EDX spectra and also the elemental composition of neat LDPE, LDPE with $2.5 \mathrm{wt} \%$ OBMFs, LDPE with $5.0 \mathrm{wt} \%$ OBMFs, LDPE with $7.5 \mathrm{wt} \%$ OBMFs and LDPE with $10.0 \mathrm{wt} \%$ OBMFs nanocomposite. Elemental analysis of this filler has been reported in a Naxos 2018 conference proceedings which showed the presence of $\mathrm{O}, \mathrm{Na}, \mathrm{Al}$, $\mathrm{Si}, \mathrm{S}, \mathrm{Cl}, \mathrm{K}, \mathrm{Ca}, \mathrm{Fe}$ and $\mathrm{Ba}$. The EDXA study here also confirmed the presence of different elements exist in clay minerals distributed in the LDPE matrix, as highlighted in Fig. 2. The lower limit of detection of EDXA is $0.01 \mathrm{wt} \%$.

\section{Morphology study of OBMFs and LDPE/OBMFs nanocomposite materials}

To identify the surface topography of reclaimed clay particles from oil based mud waste and LDPE/OBMFs nanocomposite, morphological studies were carried out by using SEM. The SEM micrographs were used to analyse the changes in morphological structure of OBMFs in LDPE matrix.

Figure 3 a shows the presence of tightly stacked clay platelets with size ranges up to $1000 \mathrm{~nm}$. Figure $3 \mathrm{~b}$ shows the cavity and uneven surfaces due to the cryogenic fracture of the sample. However, Fig. 3c shows that there are loosely dispersed OBMFs in the LDPE matrix which has higher 
Fig. 3 SEM images of (a) OBMFs; (b) neat LDPE; (c) LDPE with $2.5 \mathrm{wt} \%$ OBMFs; (d) LDPE with $5.0 \mathrm{wt} \%$ OBMFs; (e) LDPE with $7.5 \mathrm{wt} \%$ OBMFs and (f) LDPE with $10.0 \mathrm{wt} \%$ OBMFs
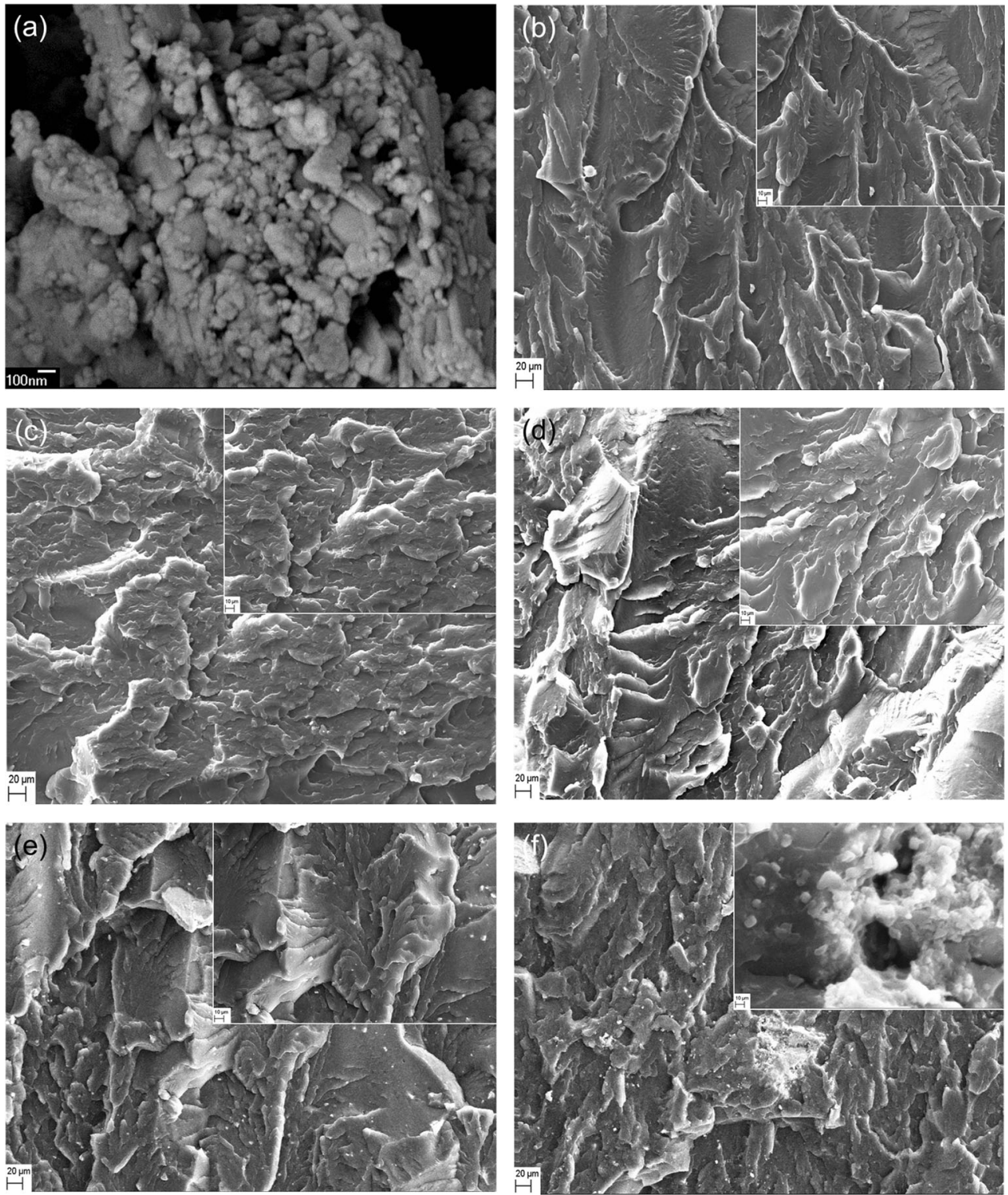

concentration of OBMFs, noticeable in the LDPE matrix in Fig. 3d. Figure 3e shows a mix of agglomeration of OBMFs and local scattered filler in LDPE matrix indicating intercalation of clay platelets. However, Fig. $3 \mathrm{f}$ shows poor dispersion of OBMFs with a remarkable agglomeration of OBMFs in the LDPE matrix.

\section{Micro-structure by XRD and TEM}

The XRD analyses are illustrated in Fig. 4 addressing the diffractograms at (a) wide angle X-ray diffraction (WAXD); (b) small angle X-ray diffraction; (c) comparing XRD patterns between MMT (as a reference) and OBMFs and (d) illustrating a few extra peaks for the LDPE polymer matrix potentially caused by adding these phases through OBMFs addition to the polymer matrix.
In Fig. 4, XRD patterns of LDPE and its nanocomposites are reported. A clear shift of the diffraction peaks of the planes (001) of OBMFs towards lower angles for the LDPE/OBMFs nanocomposites is noted. However, it can be seen that the basal spacing of OBMFs increases with different nanocomposites in different ratios. The $\mathrm{d}_{001}$ spacings were calculated using Bragg's law $n \lambda=2 d \sin \theta$, where $\lambda$ is the wavelength of $\mathrm{X}$-ray radiation used in the experiment, $d$ corresponds to the distance between diffraction lattice planes and $\theta$ is the half of the diffraction angle. Analysing different peaks from these XRD data, it can be highlighted that the basal spacing increases with the increase of filler contents in nanocomposites. The diffraction peak of OBMFs was observed at $2 \theta=11.40^{\circ}$ which corresponds to a $d$-spacing of $7.75 \AA$. The $d$-spacings of LDPE with $2.5 \mathrm{wt} \%$ and $5.0 \mathrm{wt} \%$ OBMFs nanocomposites were identified at $9.6^{\circ}$ and $5.6^{\circ}$ which corresponds to the value 

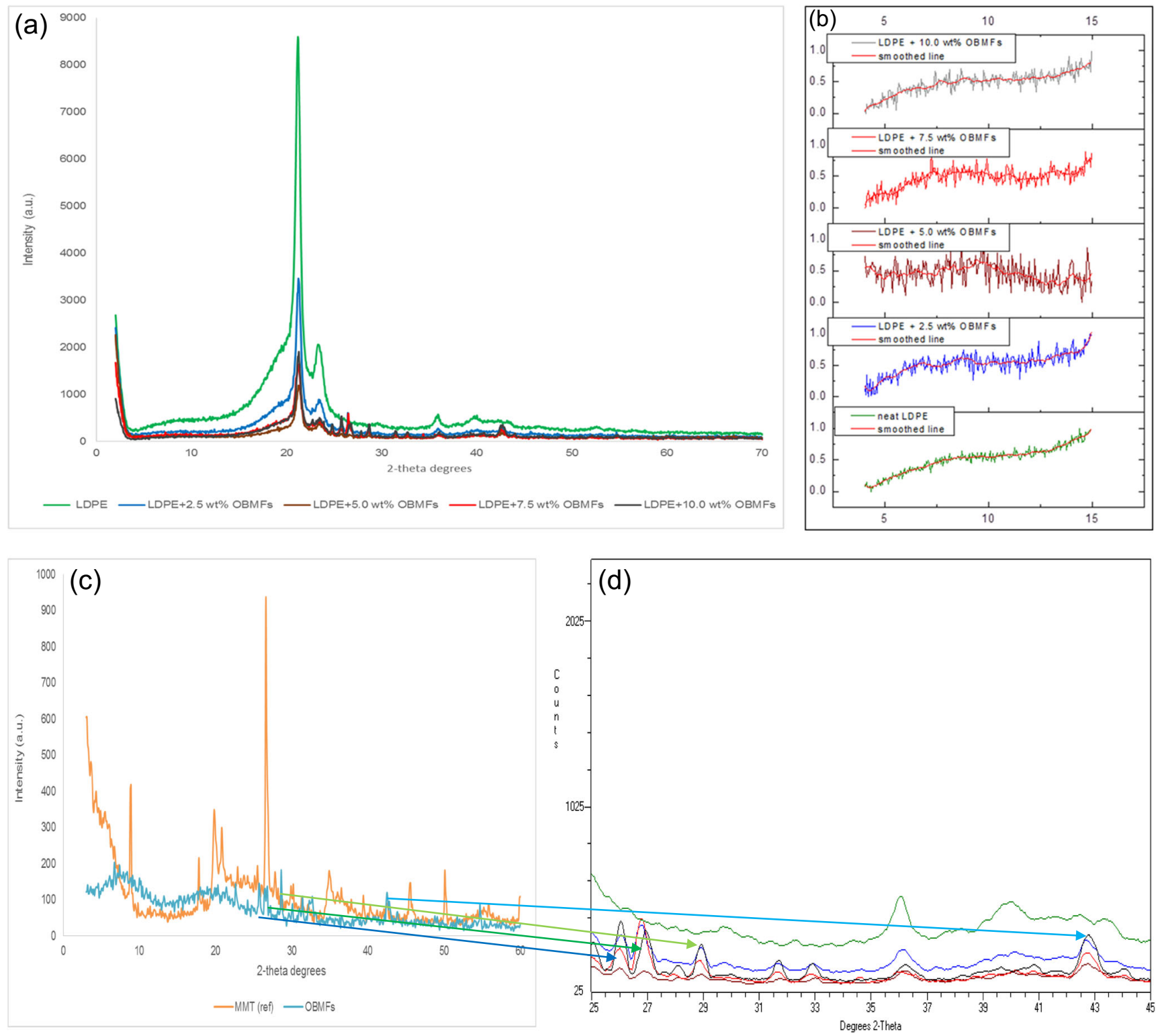

Fig. 4 Different XRD patterns of LDPE and its nanocomposites at (a) WAXD; (b) SAXD; (c) WAXD patterns of MMT and OBMFs and (d) potential peak initiation in LDPE polymer matrix due to addition with OBMFs

of $9.02 \AA$ and $15.77 \AA$, respectively. Moreover the $d$-spacings of LDPE with $7.5 \mathrm{wt} \%$ and $10.0 \mathrm{wt} \%$ OBMFs nanocomposites were determined as $9.06 \AA$ and $16.06 \AA$.

Analysing the $d$-spacing data of the corresponding peaks of reclaimed clay and LDPE/OBMFs nanocomposites, it can be highlighted here that the trend of $d$-spacings among OBMFs and LDPE/OBMFs nanocomposites are not consistent. However, the peak positions of LDPE with $5.0 \mathrm{wt} \%$ and $10.0 \mathrm{wt} \%$ OBMFs nanocomposites are noticeable. In both of these materials, the peaks of the planes (001) are shifted towards lower angles, which corresponds to the highest $d$-spacing value of these materials. This finding also agreed with the findings of the SEM (in Fig. 3) study. Based on this SEM study, it is important to mention here that LDPE with
$10.0 \mathrm{wt} \%$ OBMFs nanocomposites indicates both local exfoliation and also shows agglomeration of clay minerals in the morphology study. Considering the data obtained in this XRD analysis, it can be inferred that OBMFs is exfoliated in LDPE with $5.0 \mathrm{wt} \%$ and apparently OBMFs might locally exfoliated in the LDPE polymer matrix. Transmission electron microscopy analysis is believed to clarify the nanomorphology in more detail in the next section.

TEM analyses were carried out to validate the results obtained from thermal and morphology analyses. It can be highlighted in Fig. 5a that the clay plates are barely connected with each other, representing the exfoliation nature of the clay platelets which is also noticeable in Fig. 5b. Figure 5 b clearly shows the tendency of dispersion characteristic from 

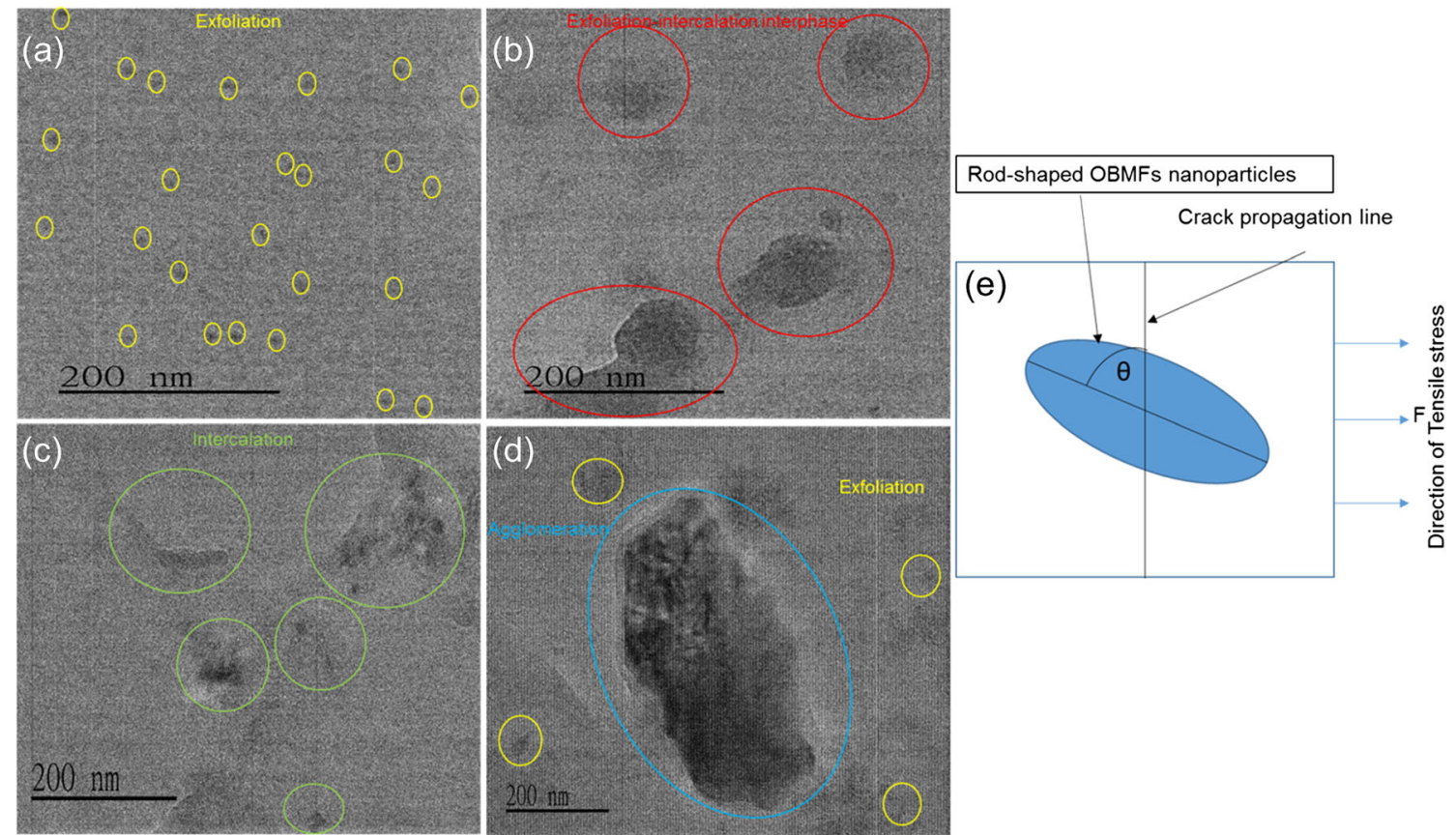

Fig. 5 TEM micrographs of (a) LDPE with 2.5 wt\% OBMFs; b LDPE with 5.0 wt\% OBMFs; $\mathbf{c}$ LDPE with 7.5 wt\% OBMFs; d LDPE with 10.0 wt\% OBMFs nanocomposite and (e) schematic diagram of nanoparticles orientation and tensile stress direction

exfoliation towards intercalation. It can be referred as the exfoliation-intercalation interphase.

In Fig. 5c, the loose but structured network of clay platelets is visible which indicates the intercalation nature of these platelets. However, the dark shades and spots in Fig. 5c highlight the agglomeration of platelets, although a few light spots indicate the local exfoliation of clay platelets.

\section{Thermal properties by DSC and TGA}

Non-isothermal DSC studies were conducted to elucidate the influence of novel filler OBMFs on the thermal degradation behaviour of nanocomposite materials. Different phases of degradation stages are shown in Fig. 6.

Analysing the DSC thermograms in Fig. 6a, it can be highlighted that there is not any significant change in the glass transition temperature of these nanocomposite materials compared to that of neat LDPE polymer. There is a minor change in glass transition temperature (less than $1{ }^{\circ} \mathrm{C}$ ) in LDPE with $2.5 \mathrm{wt} \%$ OBMFs nanocomposite. However, the melting point remains almost unchanged, only a fraction of a degree Celsius change is noticeable in Fig. 6b. Figure 6c shows a consistent higher recrystallization temperature compare to that of LDPE. These three main heat flow curves in thermograms are discussed in more detail, addressing the potential different thermal properties possessed by these materials.

There is a distinctive peak present in neat LDPE and its nanocomposites in Fig. 6b which represents the melting behaviour of alpha phase crystals associated with the materials. There is not any associated heat curve shoulder noticeable corresponding to the absence of other crystalline phases or the other phases might be very weak compared to the presence of alpha phase in the materials. Considering the thermograms in melting peaks representing the heat capacity value of LDPE and its nanocomposites, the \% of crystallinity can be identified using the following equation:

$\%$ of crystallinity $=[\Delta H m-\Delta H c] / \Delta H m^{\circ} * 100 \%$

Where $\Delta H m$ is the heat of melting, $\Delta H c$ the heat of cold crystallisation which is 0 as not present in this experiment $\left(\Delta H c=0\right.$ in this case), and $\Delta H m^{\circ}$ is a reference value if the polymer were $100 \%$ crystalline. All the units are in $\mathrm{J} / \mathrm{g}$ and the value of $\Delta \mathrm{Hm}^{\circ}$ is $293 \mathrm{~J} / \mathrm{g}$ [37]. The \% of crystallinity value of LDPE and its nanocomposites are presented in Table 3.

It is clearly evident that there is a decreasing trend of $\%$ of crystallinity as the percentage of filler content increases. The decreasing trend in the $\%$ of crystallinity degree of the nanocomposite materials can be explained by the presence of filler contents in polymer matrix, which can hinder the motion of the polymer chain segments and inhibit crystal growth.

The specific heat capacity value of LDPE and its nanocomposites have been identified by analysing the thermograms in Fig. 6c. The specific heat capacity value can be determined by the following equations:

$C_{p}=(\delta Q / \delta T)$ 

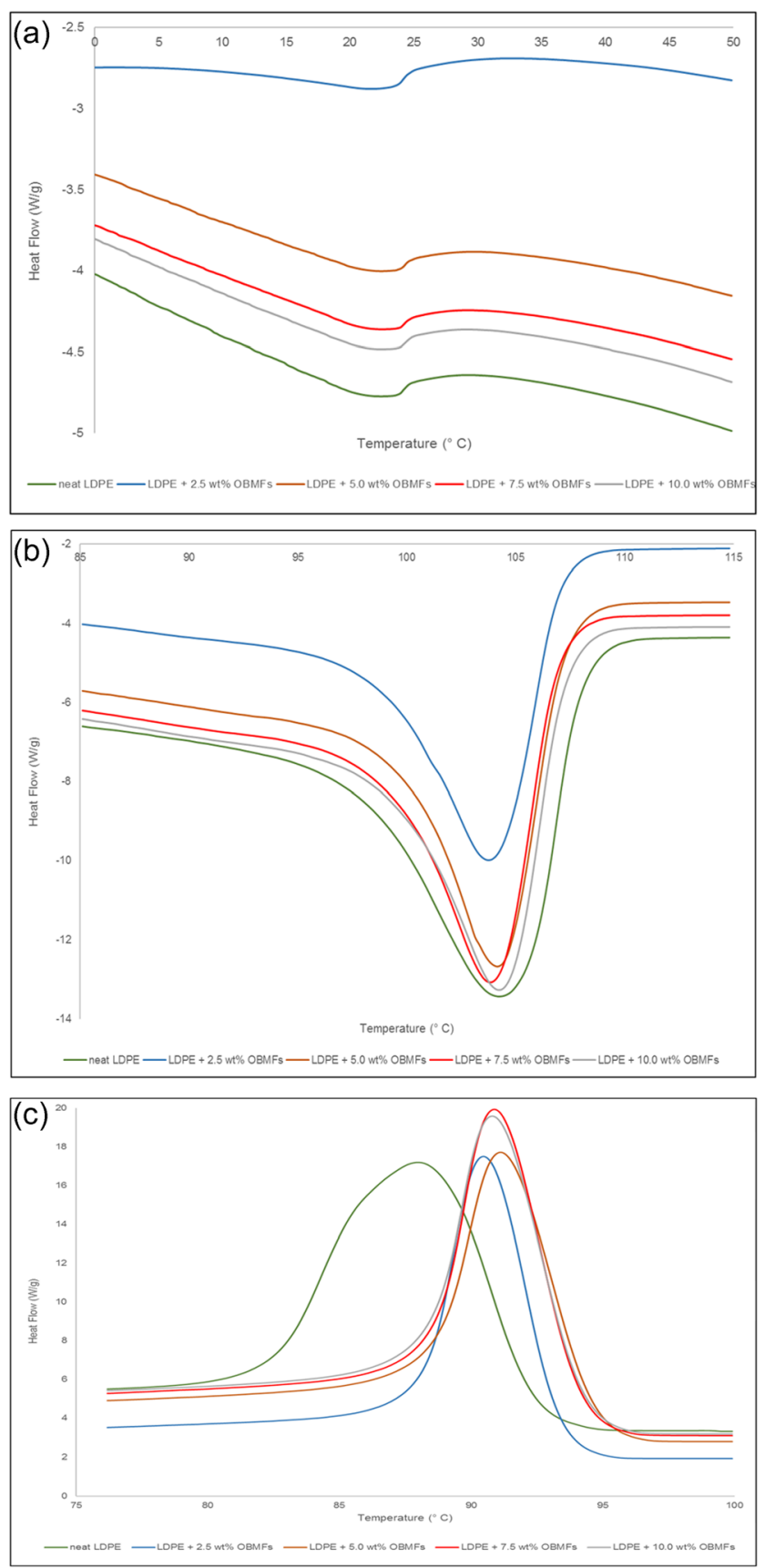

Fig. 6 DSC thermograms of LDPE and its nanocomposites at (a) $\mathrm{Tg}$; (b) $\mathrm{T}_{\mathrm{m}}$ and $(\mathbf{c}) \mathrm{T}_{\mathrm{c}}$
$C_{p}=(\delta Q / \delta t) \times(\delta t / \delta T)$

Where $C p$ is the heat capacity in Joules per Kelvin $\left(\mathrm{JK}^{-1}\right), \mathrm{Q}$ is heat energy in Joule and $\mathrm{T}$ is the temperature denoted as ${ }^{\circ} \mathrm{C}$ or $\mathrm{K} . \delta Q / \delta t$ represents the heat flow and $\delta t / \delta T$ corresponds to reciprocal heating rate. By using these two equations, the analysed specific heat capacities of neat LDPE and its nanocomposites are identified, as presented in Table 2.

The heat capacity data presented in Table 2 shows the negative effects of OBMFs in polymer matrix. However, LDPE with 2.5 and 7.5 wt\% OBMFs show higher heat capacity property in nanocomposites, LDPE with $10.0 \mathrm{wt} \%$ shows the lowest heat capacity indicating a superior thermal conductivity property of this material among different nanocomposites. The heat capacity value decreases about $21 \%$ in LDPE with $10.0 \mathrm{wt} \%$ OBMFs nanocomposite.

In addition to the SEM observation, it is also important to understand that different interphases exist between LDPE and layered silicate nanocomposites. It is believed that there are two interphases present in LDPE polymer matrix and layered silicates in OBMFs. One of these interphases represents the interphases between the crystal fraction and amorphous fraction of the polymer matrix and the other is between filler and polymer matrix [38]. To understand the thermal degradation behaviour of any nanocomposite material, it is important to identify the different phases present in the polymer matrix predominantly crystalline and amorphous phases exist in the material. Analysing the heat capacity value, $C p$ in glass transition temperature, mobile amorphous fraction (MAF) can be identified by the following equation:

$M A F=\Delta C_{p} / \Delta C_{\text {pamp }}$

Where $\Delta C_{p} / \Delta C_{p \text { amp }}$ are the heat capacity increments at the glass transition temperature of LDPE and its nanocomposites and the pure amorphous LDPE polymer, respectively. Using the MAF value, rigid amorphous fraction (RAF) can also be identified by the following equation:

$R A F=1$-crystallinity $-\Delta C_{p} / \Delta C_{p}$ amp

Table 2 Structural composition and thermal properties details of LDPE and its nanocomposites

\begin{tabular}{|c|c|c|c|c|}
\hline Material & $\%$ of crystallinity & $\mathrm{RAF}=1-\mathrm{MAF}-\mathrm{CF}$ & $\operatorname{MAF}\left(\Delta C_{p} / \Delta C_{p(\mathrm{am})}\right)$ & Specific heat capacity $(C p) \mathrm{JK}^{-1} \mathrm{~kg}^{-1}$ \\
\hline LDPE & 16.71 & 0.13 & 0.70 & 4828 \\
\hline LDPE+2.5 wt $\%$ OBMFs & 13.00 & 0.29 & 0.58 & 3990 \\
\hline LDPE+5.0 wt $\%$ OBMFs & 12.48 & 0.28 & 0.59 & 3891 \\
\hline LDPE+7.5 wt $\%$ OBMFs & 12.48 & 0.23 & 0.64 & 4160 \\
\hline LDPE+10.0 wt $\%$ OBMFs & 11.07 & 0.31 & 0.58 & 3794 \\
\hline
\end{tabular}


Table 3 TGA analysis at different decomposition stages of LDPE and its nanocomposites with different clay contents

\begin{tabular}{lllll}
\hline Material & $\mathrm{T}_{\mathrm{D} 5 \%}\left({ }^{\circ} \mathrm{C}\right)$ & $\mathrm{T}_{\mathrm{D} 50 \%}\left({ }^{\circ} \mathrm{C}\right)$ & $\mathrm{D} 1 / 2$ Time & Residue $(\% \mathrm{wt})$ at $1000{ }^{\circ} \mathrm{C}$ \\
\hline LDPE & 381.27 & 448.42 & 45.03 & 0.22 \\
LDPE+2.5 wt\% OBMFs & 321.24 & 413.14 & 44.34 & 1.27 \\
LDPE+5.0 wt\% OBMFs & 336.26 & 427.18 & 43.79 & 4.01 \\
LDPE+7.5 wt\% OBMFs & 313.73 & 395.60 & 43.81 & 5.40 \\
LDPE+10.0 wt\% OBMFs & 340.83 & 449.72 & 45.68 & 7.24 \\
\hline
\end{tabular}

Using the eqs. (4) and (5), the MAF and RAF values are identified and presented in Table 2.

It can be highlighted here that although RAF is non-crystalline, it does not participate in the glass transition due to the parts of the molecules are fixed due to the immobilisation of molecules in the polymer chain $[38,39]$. The crystalline fraction in polymer chain, inorganic based filler (OBMFs) (assumed mostly in crystalline phase) and RAF incurs immobilisation in the polymer chain which is evident in the data presented in Table 2. It is also manifested based on the data presented in Table 2 that the RAF value is increased more than
$100 \%$ in nanocomposites compared to that of neat LDPE. The reason can be explained that the incremental filler content acts as a nucleating agent and increases the nucleation ratio.

Thermal degradation of LDPE/OBMFs nanocomposites has been studied under a dry nitrogen environment using a TA instrument TGA Q500.

The degradation scenario of these materials at different heating stages are analysed and the key findings are presented in Table 3.

The onset degradation temperature of these materials are identified at weight $\%$ losses of $5 \%$ and $50 \%$. In both cases,
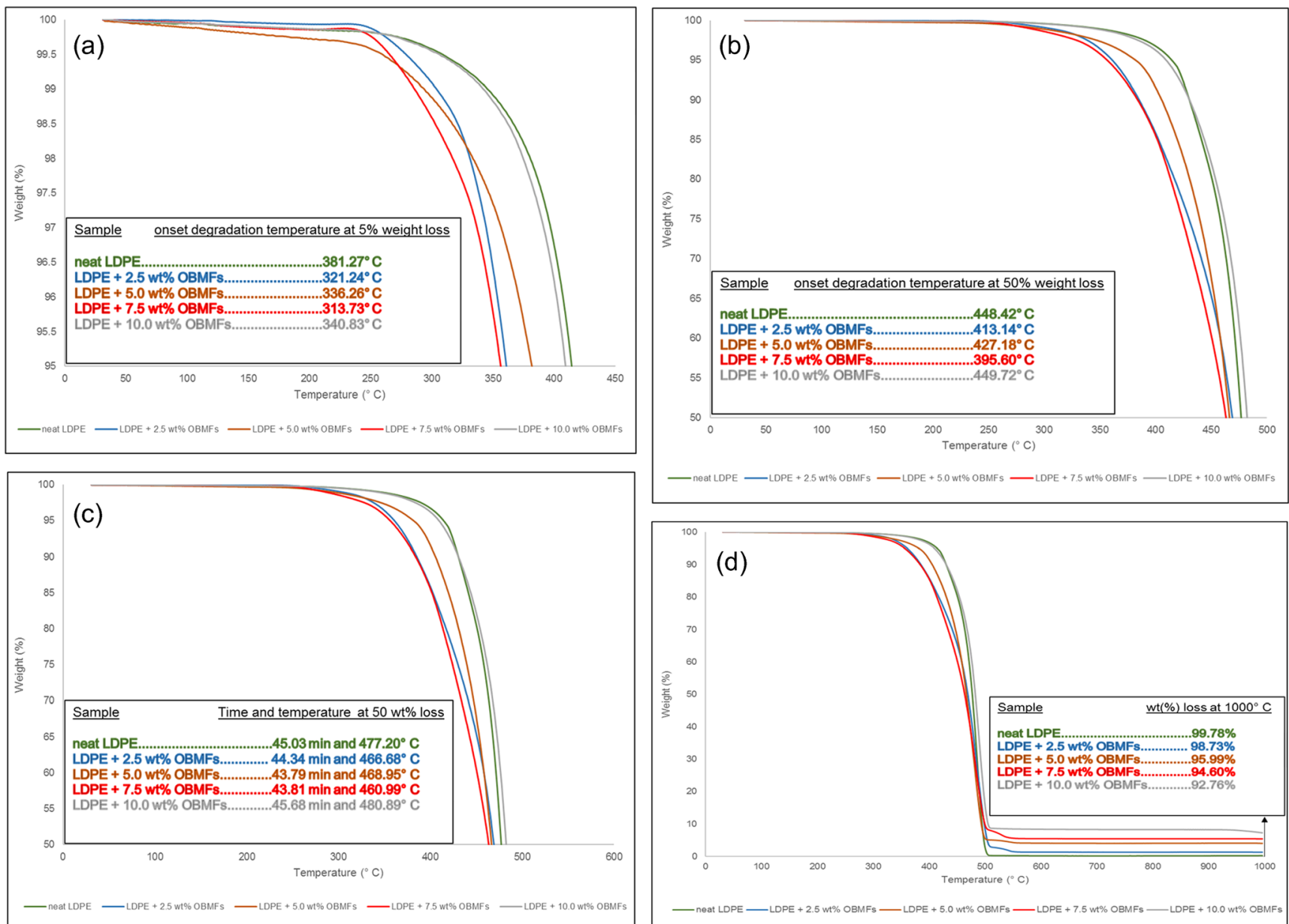

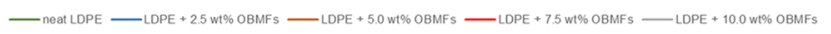

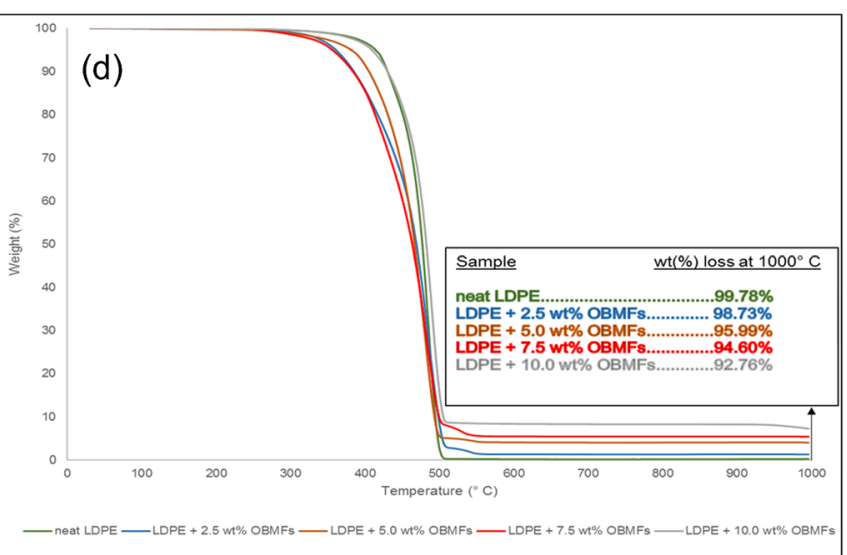

Fig. 7 TGA thermograms of LDPE and its nanocomposites at: a onset degradation at 5\% weight loss; $\mathbf{b}$ onset degradation at $50 \%$ weight loss; $\mathbf{c}$ D-half (50\% weight loss) time and (d) residue at $1000{ }^{\circ} \mathrm{C}$ 

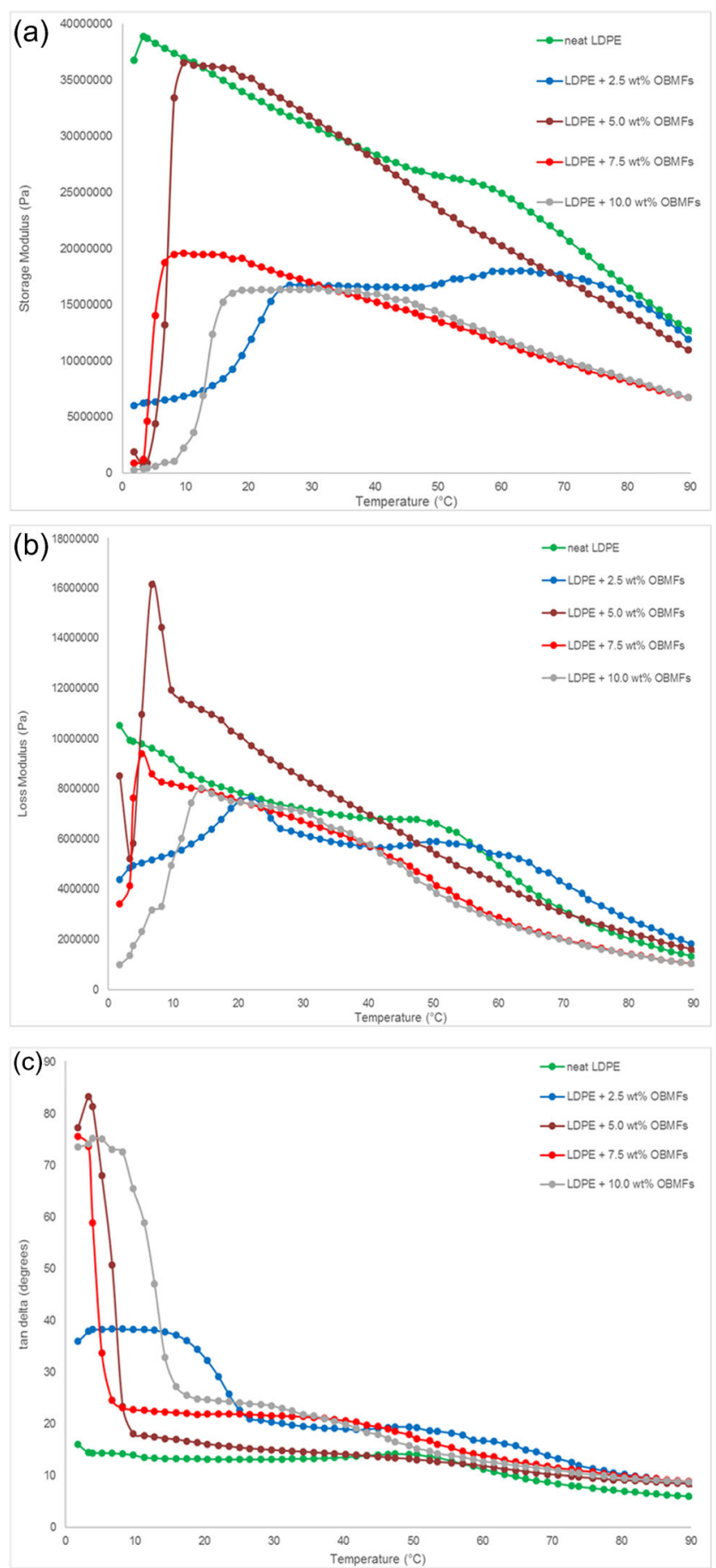

Fig. 8 Variation of (a) storage modulus, $\mathbf{b}$ loss modulus and (c) damping intensity $(\tan \delta)$ with temperature of LDPE and its nanocomposites

LDPE with $10 \mathrm{wt} \%$ OBMFs shows the highest onset degradation temperature among the nanocomposites with different wt\% filler contents which represents LDPE with $10 \mathrm{wt} \%$ OBMFs nanocomposite possessing the highest thermal stability. However, the thermal stability property is significantly affected in LDPE with $7.5 \mathrm{wt} \%$ OBMFs. Considering the lowest temperature at D-half ( $50 \%$ weight loss), the presence of peak assignments representing amorphous phase in FTIR analysis and heat capacity value from DSC analysis, it can be inferred here that LDPE with $7.5 \mathrm{wt} \%$ OBMFs possesses a good heat capacity property. It is also noticeable that the addition of OBMFs into LDPE matrix significantly reduces the thermal stability of the material based on $\mathrm{T}_{\mathrm{D} 5 \%}$ and $\mathrm{T}_{\mathrm{D} 50 \%}$ data.

However, the degradation trend is distinctly noticeable as it does not show any significant changes of weight loss $\%$ until $300{ }^{\circ} \mathrm{C}$. Degradation mainly occurred between 300 and $500{ }^{\circ} \mathrm{C}$ and the poor thermal stability of nanocomposites is clearly visible except for LDPE with $10 \mathrm{wt} \%$ OBMFs nanocomposite. In Fig. 7c, LDPE with $10 \mathrm{wt} \%$ OBMFs shows the longest time needed to reach the D-half point which also indicates superior thermal stability property among the samples. It is also manifested in this figure that at this D-half point LDPE with $10 \mathrm{wt} \%$ OBMFs shows the highest temperature which gives an indication of improving of thermal conductivity property of this material. It is also verified with the lowest heat capacity value obtained from DSC study. It is articulated here that the incremental filler contents may have a strong influence on the thermal stability of LDPE/OBMFs nanocomposites. Filler contents up to $10 \mathrm{wt} \%$ reduce the thermal stability of the materials whereas LDPE with $10 \mathrm{wt} \%$ possesses the best thermal stability and thermal conductivity properties among the nanocomposites with different wt\% filler content.

\section{Dynamic mechanical properties}

The storage modulus $\left(E^{\prime}\right)$ represents the load bearing capacity of a material. The effect of OBMFs in influencing this storage modulus is graphically enumerated in Fig. 8a. It is noticeable from Fig. 8a that there was a significant decrease in the storage modulus of LDPE/OBMFs nanocomposites compared to the storage modulus of neat LDPE matrix. This is perhaps due to the decrease in the stiffness of LDPE matrix with the reinforcing effect of the fillers prone to decrease in stress transfer at the interfacial surface. As noticeable in Fig. 8a, the storage modulus decreased drastically with the increase in temperature and the degree of storage modulus drop was significant in the temperature regions between 20 and $70{ }^{\circ} \mathrm{C}$.

The loss modulus curves of neat LDPE and its nanocomposites are presented in Fig. 8b which shows a relaxation peak at $50{ }^{\circ} \mathrm{C}$ in neat LDPE decreased to lower temperatures for nanocomposites such as the peaks were at $25^{\circ} \mathrm{C}, 10{ }^{\circ} \mathrm{C}, 5^{\circ} \mathrm{C}$ and $15^{\circ} \mathrm{C}$ for LDPE with 2.5, 5.0, 7.5 and $10.0 \mathrm{wt} \%$ OBMFs respectively. There is a significant changes in loss modulus noticeable in the temperature regions between 40 to $55{ }^{\circ} \mathrm{C}$ which clearly shows the loss modulus is higher for LDPE with 2.5 and $5.0 \mathrm{wt} \%$ OBMFs compared to that of neat LDPE. 
However, the loss modulus decreased in LDPE with 7.5 and $10.0 \mathrm{wt} \%$ OBMFs in those temperature regions. This trend is also clearly shown between 70 to $90^{\circ} \mathrm{C}$ temperature regions. This trend completely agreed with the tensile results mentioned in the next section. The equipment which we used for rheology analysis (TA AR1000) is associated with an open hot plate which is not environmentally controlled and we assume the temperature reading in the software may be not the same as the actual temperature in the sample due to the heat absorption by the samples and heat dissipation from the hot plate to open air. It is noticeable that loss modulus reduced drastically from $40{ }^{\circ} \mathrm{C}$ which we assume is nearly in the same room temperature the tensile tests were performed at $25^{\circ} \mathrm{C}$.

The ratio of loss modulus to storage modulus is measured which is graphically presented in Fig. $8 \mathrm{c}$ to identify the damping properties of the materials. The damping peak in the nanocomposites showed an increased magnitude of $\tan \delta$ in comparison to neat LDPE. This graph represents the balance between the elastic phase and viscous phase in the polymeric structure. It is noticeable the maximum peak of neat LDPE at $50{ }^{\circ} \mathrm{C}$ which is assumed $\mathrm{Tg}$ of neat LDPE shifted significantly to lower temperatures for LDPE/OBMFs nanocomposites (Fig. 9).

\section{Tensile properties of LDPE/OBMFs nanocomposites}

The mechanical properties of LDPE/OBMFs nanocomposites are presented in Table 4.

It can be seen that the addition of $10.0 \mathrm{wt} \%$ OBMFs can improve tensile strength and elongation at break by $17.5 \%$ and $13.7 \%$ respectively. However the tensile strength and elongation at break of other nanocomposites are remained almost same as tensile strength and elongation at break of neat LDPE. There is an increasing trend of improving tensile modulus among nanocomposites, but only LDPE with $7.5 \mathrm{wt} \%$ and $10.0 \mathrm{wt} \%$ nanocomposites show higher tensile modulus than that of neat LDPE.

The improvement in mechanical properties of Polyethylene/clay nanocomposites were reported by using compatibilisers by different researchers [40-42]. However, in our recent studies on LDPE/OBMFs nanocomposites, it is clearly noticeable that there is a little but consistent improvement in tensile property among LDPE/OBMFs nanocomposites. A slight decrease in the tensile strength and modulus can be observed when the OBMFs loading increases from 0 to $5.0 \mathrm{wt} \%$. The significant enhancement in the tensile strength and modulus were obtained with $7.5 \mathrm{wt} \%$ and $10.0 \mathrm{wt} \%$ OBMFs loading. In addition the decrease trend of elongation at break may be attributed to a reduction in deformability of the rigid interface between nanofillers and matrix [43]. The OBMFs used in this study are nanoparticle in considering size and shape, but observing the micrographs in Fig. 5 it can be highlighted that without adding any grafting compatibilisers, the OBMFs nanoparticles are uniformly dispersed and no agglomeration is noticeable in LDPE with $2.5 \mathrm{wt} \%$ and $5.0 \mathrm{wt} \%$ fillers loading which are difficult to visualise in SEM images in Fig. 3. However, the orientation of nanoparticles due to the OBMFs compatibility facilitate to act this nanoparticle in a similar manner as fibre which is highlighted in Fig. 5e. After observing carefully the TEM micrographs in Fig. 5a-d, schematic diagrams are presented in Fig. 5e considering the applied force in tensile test and the direction in nanoparticles orientation. It is noticeable that the gradient between nanoparticle orientation and crack propagation plane is decreasing with the increase of filler contents in LDPE matrix which may be attributed to an improvement in materials strength predominantly the fracture strength.
Fig. 9 Tensile stress-strain curves of neat LDPE and its nanocomposites

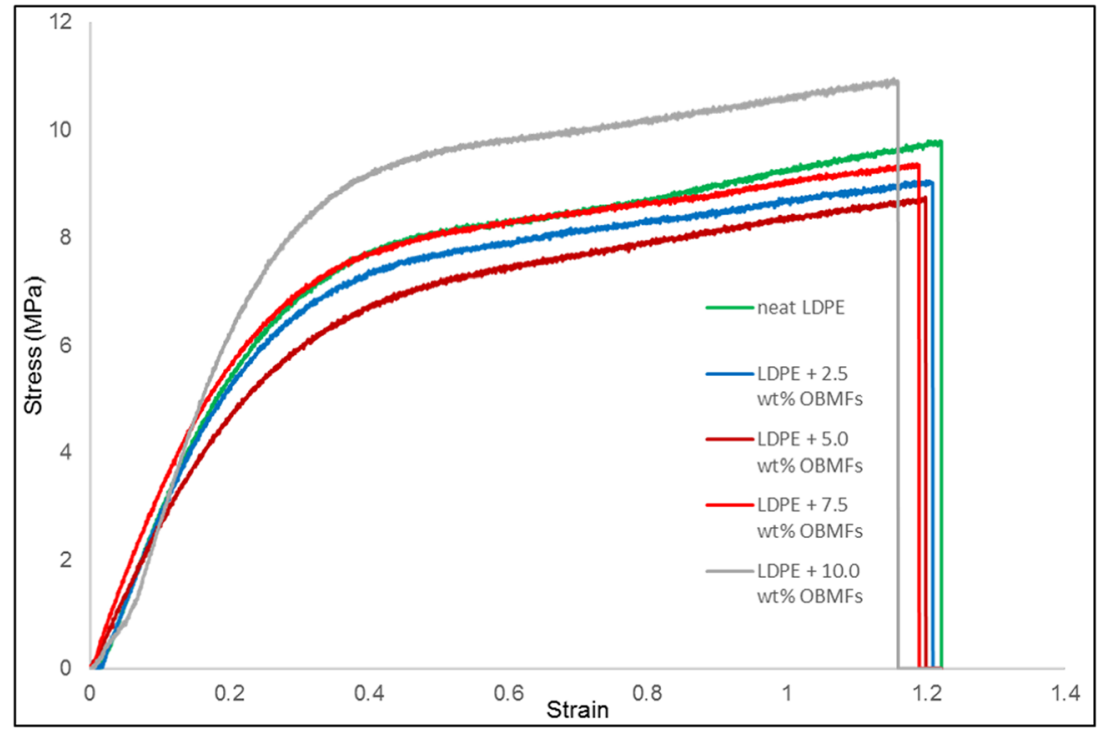


Table 4 Mechanical properties of LDPE and its nanocomposites

\begin{tabular}{llll}
\hline Sample & Tensile modulus (MPa) & Tensile strength (MPa) & Elongation at break (\%) \\
\hline LDPE & $28 \pm 1.1$ & $8.0 \pm 0.4$ & $66 \pm 4$ \\
LDPE+2.5 wt\% OBMFs & $26 \pm 1.6$ & $7.5 \pm 0.2$ & $64 \pm 6$ \\
LDPE+5.0 wt\% OBMFs & $27 \pm 1.4$ & $7.2 \pm 0.1$ & $62 \pm 3$ \\
LDPE+7.5 wt\% OBMFs & $31 \pm 1.1$ & $7.9 \pm 0.4$ & $61 \pm 5$ \\
LDPE+10.0 wt\% OBMFs & $32 \pm 1.2$ & $9.4 \pm 0.1$ & $57 \pm 4$ \\
\hline
\end{tabular}

\section{Conclusions}

A series of the LDPE/OBMFs nanocomposites with OBMFs content ranging from $2.5-10 \mathrm{wgt} \%$ has been prepared by using a melt-blending technique in a twin-screw extruder. The structure of the LDPE/OBMFs nanocomposites was presented using XRD, SEM and TEM. The thermal degradation behaviour of the LDPE/OBMFs nanocomposites was demonstrated by using DSC and TGA. The results of XRD, SEM and TEM indicate that the LDPE/OBMFs nanocomposites are a hybrid material consisting of OBMFs nanoplatelets and LDPE polymer matrix. Moreover, it is highlighted that the OBMFs nanoplatelets exist as aggregates and contribute to different dispersion behaviour with a change of OBMFs content in the LDPE matrix. In this study, OBMFs shows exfoliation characteristics with LDPE with $5.0 \mathrm{wt} \%$ OBMFs nanocomposites whereas these show structure intercalation in LDPE with $7.5 \mathrm{wt} \%$ OBMFs. In addition, OBMFs create a mix of agglomeration and local exfoliation which was detectable by thermal analysis.

The thermal properties of the LDPE and its nanocomposites were studied by means of DSC and TGA. No changes in melting and recrystallization temperatures due to the addition of OBMFs in the polymer matrix were detected. However, there was a decrease in the percentage of crystallinity noticeable with an increase in filler content. In addition, heat capacity reduced in nanocomposites compared to the neat LDPE matrix which indicate the inclusion of OBMFs in LDPE improves the thermal conductivity of these nanocomposites in general. LDPE with $10.0 \mathrm{wt} \%$ OBMFs nanocomposites showed the lowest heat capacity (about $21 \%$ reduction) addressing the superior thermal conductivity of this material. A significant increase of thermal stability was also achieved with LDPE with $10.0 \mathrm{wt} \%$ OBMFs nanocomposite. Furthermore, the viscoelastic investigation revealed the storage modulus, loss modulus and damping intensity properties of materials which also agreed with the mechanical properties of the material. LDPE with $10.0 \mathrm{wt} \%$ of OBMFs content showed both thermal stability and superior tensile properties compared to those properties of neat LDPE and LDPE with 2.5, 5.0 and $7.5 \mathrm{wt} \%$ OBMFs content nanocomposites.
Acknowledgements The authors are indebted to Dr. Laurie Smith from School of Pharmacy and Life Sciences, Robert Gordon University, Aberdeen for skilful technical assistance, helpful discussion and supplying laboratory facility.

Open Access This article is distributed under the terms of the Creative Commons Attribution 4.0 International License (http:// creativecommons.org/licenses/by/4.0/), which permits unrestricted use, distribution, and reproduction in any medium, provided you give appropriate credit to the original author(s) and the source, provide a link to the Creative Commons license, and indicate if changes were made.

\section{References}

1. Moniruzzaman M, Winey KI (2006) Polymer nanocomposites containing carbon nanotubes. Macromolecules. 39(16):5194-5205

2. Potts JR, Dreyer DR, Bielawski CW, Ruoff RS (2011) Graphenebased polymer nanocomposites. Polymer. 52(1):5-25

3. Jordan J, Jacob KI, Tannenbaum R, Sharaf MA, Jasiuk I (2005) Experimental trends in polymer nanocomposites - a review. Mater Sci Eng A 393(1-2):1-1

4. Sahoo NG, Rana S, Cho JW, Li L, Chan SH (2010) Polymer nanocomposites based on functionalized carbon nanotubes. Prog Polym Sci 35(7):837-867

5. Usuki A, Hasegawa N, Kato M, Kobayashi S (2005) Polymer-clay nanocomposites. InInorganic polymeric nanocomposites and membranes. Springer, Berlin, Heidelberg, pp 135-195

6. Okada A, Usuki A (2006) Twenty years of polymer-clay nanocomposites. Macromol Mater Eng 291(12):1449-1476

7. Choudalakis G, Gotsis AD (2009) Permeability of polymer/clay nanocomposites: a review. Eur Polym J 45(4):967-984

8. Gilman JW (1999) Flammability and thermal stability studies of polymer layered-silicate (clay) nanocomposites1. Appl Clay Sci 15(1-2):31-49

9. Pappalardo S, Russo P, Acierno D, Rabe S, Schartel B (2016) The synergistic effect of organically modified sepiolite in intumescent flame retardant polypropylene. Eur Polym J 76:196-207

10. Sheng N, Boyce MC, Parks DM, Rutledge GC, Abes JI, Cohen RE (2004) Multiscale micromechanical modeling of polymer/clay nanocomposites and the effective clay particle. Polymer. 45(2): 487-506

11. Peeterbroeck S, Alexandre M, Nagy JB, Pirlot C, Fonseca A, Moreau N, Philippin G, Delhalle J, Mekhalif Z, Sporken R, Beyer G (2004) Polymer-layered silicate-carbon nanotube nanocomposites: unique nanofiller synergistic effect. Compos Sci Technol 64(15):2317-2323

12. Sachse S, Silva F, Zhu H, Irfan A, Leszczyńska A, Pielichowski K, Ermini V, Blazquez M, Kuzmenko O, Njuguna J (2012) The effect of nanoclay on dust generation during drilling of PA6 nanocomposites. J Nanomater 2012:26 
13. Fu X, Qutubuddin S (2001) Polymer-clay nanocomposites: exfoliation of organophilic montmorillonite nanolayers in polystyrene. Polymer. 42(2):807-813

14. Costa FR, Wagenknecht U, Heinrich G (2007) LDPE/Mg-Al layered double hydroxide nanocomposite: thermal and flammability properties. Polym Degrad Stab 92(10):1813-1823

15. Wen X, Wang Y, Gong J, Liu J, Tian N, Wang Y, Jiang Z, Qiu J, Tang T (2012) Thermal and flammability properties of polypropylene/carbon black nanocomposites. Polym Degrad Stab 97(5):793-801

16. Zhao C, Qin H, Gong F, Feng M, Zhang S, Yang M (2005) Mechanical, thermal and flammability properties of polyethylene/ clay nanocomposites. Polym Degrad Stab 87(1):183-189

17. Shah RK, Paul DR (2006) Organoclay degradation in melt processed polyethylene nanocomposites. Polymer. 47(11):4075-4084

18. Zhang J, Wilkie CA (2003) Preparation and flammability properties of polyethylene-clay nanocomposites. Polym Degrad Stab 80(1): 163-169

19. Kashiwagi T, Du F, Douglas JF, Winey KI, Harris Jr RH, Shields JR (2005) Nanoparticle networks reduce the flammability of polymer nanocomposites. Nat Mater 4(12):928-933

20. Blum A, Ames BN (1977) Flame-retardant additives as possible cancer hazards. Science. 195(4273):17-23

21. Lu SY, Hamerton I (2002) Recent developments in the chemistry of halogen-free flame retardant polymers. Prog Polym Sci 27(8): $1661-1712$

22. Sain M, Park SH, Suhara F, Law S (2004) Flame retardant and mechanical properties of natural fibre-PP composites containing magnesium hydroxide. Polym Degrad Stab 83(2):363-367

23. Khan MJ, Al-Juhani AA, Shawabkeh R, Ul-Hamid A, Hussein IA (2011) Chemical modification of waste oil fly ash for improved mechanical and thermal properties of low density polyethylene composites. J Polym Res 18(6):2275-2284

24. Giri SK, Pradhan GC, Das N (2014) Thermal, electrical and tensile properties of synthesized magnetite/polyurethane nanocomposites using magnetite nanoparticles derived from waste iron ore tailing. J Polym Res 21(5):446

25. Shih YF, Chou MY, Chang WC, Lian HY, Chen CM (2017) Completely biodegradable composites reinforced by the cellulose nanofibers of pineapple leaves modified by eco-friendly methods. J Polym Res 24(11):209

26. Haque MM, Islam MS, Islam MN (2012) Preparation and characterization of polypropylene composites reinforced with chemically treated coir. J Polym Res 19(5):9847

27. Wang Y, Huang G, Zheng J (2016) Mechanochemistry modified waste rubber powder and its application in hydrogel. J Polym Res 23(12):259

28. Vlaev L, Turmanova S, Dimitrova A (2009 Mar 1) Kinetics and thermodynamics of water adsorption onto rice husks ash filled polypropene composites during soaking. J Polym Res 16(2):151164

29. Caenn R, Chillingar GV (1996) Drilling fluids: state of the art. J Pet Sci Eng 14(3-4):221-230

30. Berthezene N, De Hemptinne JC, Audibert A, Argillier JF (1999) Methane solubility in synthetic oil-based drilling muds. J Pet Sci Eng 23(2):71-81
31. Zhong H, Qiu Z, Huang W, Cao J (2011) Shale inhibitive properties of polyether diamine in water-based drilling fluid. J Pet Sci Eng 78(2):510-515

32. Onwukwe SI, Nwakaudu MS (2012) Drilling wastes generation and management approach. International Journal of Environmental Science and Development 3(3):252

33. Costa FR, Abdel-Goad M, Wagenknecht U, Heinrich G (2005) Nanocomposites based on polyethylene and $\mathrm{Mg}-\mathrm{Al}$ layered double hydroxide. I Synthesis and characterization Polymer 46(12):44474453

34. Lu H, Hu Y, Li M, Chen Z, Fan W (2006) Structure characteristics and thermal properties of silane-grafted-polyethylene/clay nanocomposite prepared by reactive extrusion. Compos Sci Technol 66(15):3035-3039

35. Morlat-Therias S, Fanton E, Gardette JL, Dintcheva NT, La Mantia FP, Malatesta V (2008) Photochemical stabilization of linear lowdensity polyethylene/clay nanocomposites: towards durable nanocomposites. Polym Degrad Stab 93(10):1776-1780

36. Zanetti M, Bracco P, Costa L (2004) Thermal degradation behaviour of PE/clay nanocomposites. Polym Degrad Stab 85(1):657665

37. Gaska K, Xu X, Gubanski S, Kádár R (2017) Electrical, mechanical, and thermal properties of LDPE graphene nanoplatelets composites produced by means of melt extrusion process. Polymers. 9(1): 11

38. Wurm A, Ismail M, Kretzschmar B, Pospiech D, Schick C (2010) Retarded crystallization in polyamide/layered silicates nanocomposites caused by an immobilized interphase. Macromolecules. 43(3):1480-1487

39. Craig DQ, Kett VL, Murphy JR, Price DM (2001) The measurement of small quantities of amorphous material - should we be considering the rigid amorphous fraction? Pharm Res 18(8):10811082

40. Singh VP, Kapur GS, Choudhary V (2016) High-density polyethylene/needle-like sepiolite clay nanocomposites: effect of functionalized polymers on the dispersion of nanofiller, melt extensional and mechanical properties. RSC Adv 6(64):59762-59774

41. Wang KH, Choi MH, Koo CM, Choi YS, Chung IJ (2001) Synthesis and characterization of maleated polyethylene/clay nanocomposites. Polymer. 42(24):9819-9826

42. Arrakhiz FZ, El Achaby M, Malha M, Bensalah MO, Fassi-Fehri O, Bouhfid R, Benmoussa K, Qaiss A (2013) Mechanical and thermal properties of natural fibers reinforced polymer composites: Doum/low density polyethylene. Mater Des 43:200-205

43. Fu SY, Lauke B (1996) Effects of fiber length and fiber orientation distributions on the tensile strength of short-fiber-reinforced polymers. Compos Sci Technol 56(10):1179-1190

Publisher's note Springer Nature remains neutral with regard to jurisdictional claims in published maps and institutional affiliations. 